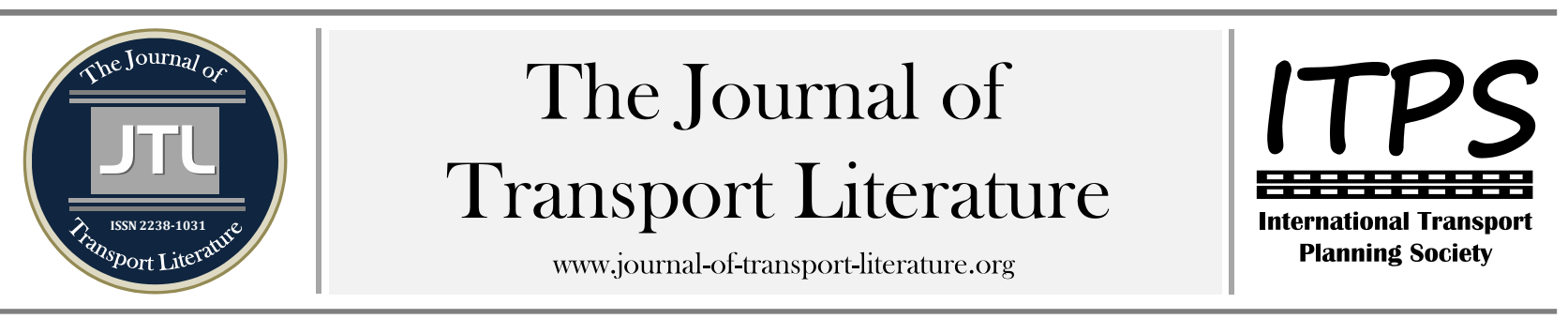

\title{
A estimação neural de tempos de viagens de ônibus sob regime de fretamento usando- se de dados de posicionamento por satélites (GPS)
}

\author{
Antonio Wagner Lopes Jales ${ }^{1,+}$; Carlos Augusto Uchôa da Silva²; \\ ${ }^{1}$ VALE S/A, São Luís, Brasil \\ 2 Universidade Federal do Ceará, Fortaleza, Brasil
}

\section{Article Info}

Palavras-chave:

Redes Neurais Artificiais

Fretamento

Previsão de tempo de

chegada

Sistema de Informações

Geográficas (SIG)

Submitted 2 Jan 2015;

received in revised form 18 Jun 2015 ;

accepted 12 Jul 2015

Licensed under

Creative Commons

CC-BY $3.0 \mathrm{BR}$

\section{Resumo}

0 trabalho teve o objeto o desenvolvimento de um modelo de previsão de chegada de ônibus que fazem o transporte de empregados sob o regime de fretamento. Para tanto, utilizou-se um modelo matemático baseado em Redes Neurais Artificiais. As experiências anteriores de aplicação de RNA's para modelagem desse tipo de problema consideraram como dados de entrada, informações "estáticas" do percurso, como por exemplo, a posição dos pontos de paradas pré-estabelecidos, a distância entre os mesmos, a velocidade média de percurso previamente analisada. A contribuição do presente trabalho foi desenvolver um modelo de aprendizado considerando como dados de entrada, qualquer localização do veículo (longitude e latitude) ao longo do percurso bem como a hora em que o mesmo passou pela mesma coordenada, tornando o modelo mais dinâmico e simplificado para ser reproduzido e incorporado às ferramentas de rastreamento veicular que utilizam posicionamento global (GPS). Outra contribuição metodológica foi a estruturação de uma "árvore de testes" que considerou variações na tipologia, nos valores para Taxa de Aprendizagem e "Momentum". O resultado alcançado chegou a um modelo de previsão com erro relativo médio de menos de $1 \%$.

+ Corresponding author. Avenida dos Portugueses, S/N, Itaqui-Bacanga, CEP 65.000-000, São Luís-MA

E-mail address: wagner_jales@yahoo.com.br

\section{Introdução}

O objetivo do trabalho foi desenvolver um método de previsão de "tempo de chegada" em um determinado ponto de controle, para aplicação no transporte de passageiros que considerasse o mínimo de informações de entrada possíveis, no caso, dados de posicionamento global do veículo em qualquer ponto do percurso capturados através de sistema de rastreamento veicular e a ferramenta adotada foi Redes Neurais Artificiais (RNA).

Nas experiências pesquisadas até então, os autores focam na modelagem para o transporte público que possuem algumas características diferentes do transporte sob regime de fretamento. 0 transporte público, por exemplo, executa o mesmo percurso diversas vezes ao longo do dia sendo que cada viagem é submetida a uma condição diferente do tráfego urbano (hora-pico, entre picos, fora do pico) enquanto no transporte sob regime de fretamento a repetição da viagem ocorre em horários específicos onde à condição de tráfego é similar, pois o serviço é prestado nas horas de pico (pico da manhã e da tarde). 0 presente trabalho focou-se na modelagem do transporte fretado onde o impacto do tráfego urbano na execução do percurso não é considera suas variações ao longo do dia, mas sim as variações que ocorrem no mesmo horário em diferentes dias da semana.

Até então, alguns autores que testaram RNA's para o mesmo fim, consideraram grande número de variáveis de entrada como, por exemplo, distância entre pontos de parada, tempo de percurso do ponto de parada anterior para o ponto de parada atual, velocidade do fluxo de veículos, etc. Em alguns casos, precisaram estimar informações complementares para, em seguida, estimar o tempo de chegada a um determinado ponto de parada, a exemplo de informações complementares tem-se o tempo de embarque dos passageiros ou a velocidade média de percurso. 0 trabalho buscou simplificar a forma de modelar considerando como dados de entrada apenas a coordenada do veículo em um dado ponto do percurso mais o horário em que o mesmo passa por tal ponto (dados estes que podem ser escolhidos aleatoriamente, em dias diferentes e em qualquer ponto do percurso).

A simplificação na forma de modelar e a qualidade do resultado só foi viável, pois a RNA possui a robustez necessária para absorver, durante o processo de aprendizagem, a influencia de variáveis que causam impacto na execução do percurso (flutuações de tráfego, tempo de embarque, distancia entre pontos de parada, características do veículo, estilo de direção do motorista, etc.) bem como o erro de precisão da localização do veículo via GPS. Outra contribuição relevante do presente artigo foi o uso de "validação cruzada" no processo de treinamento adotando-se uma árvore de testes que continha 3 seleções aleatórias diferentes para os grupos "treinamento", "validação" e "teste". Testaram-se também variações nos parâmetros de Taxa de Aprendizagem e Momentum, pois os mesmos influenciam na forma como a RNA aprendeu com os dados informados, este recurso também não foi observado em trabalhos anteriores. 0 resultado foi um modelo que fornece um Erro Relativo Médio (ERM) menor que 1\%, ou seja, em média, a diferença entre a hora apontada e a hora estimada em 
que o veículo passou por um determinado ponto pode ser acompanhada na escala de segundos. Do ponto de vista operacional, erros nessa escala são aceitáveis e o modelo auxilia tanto quem faz a gestão do serviço quanto quem usa o mesmo.

\section{A Modelagem de Tempos de Chegada}

A partir de dados coletados do sistema de rastreamento veicular instalado em ônibus que fazem uma rota do transporte público na cidade de Toronto (USA), Shalaby (2004) modelou separadamente, o tempo em que o veículo permanece na parada para embarque/desembarque de passageiros e o tempo de percurso do veículo executando a referida rota. 0 autor comparou a eficiência de quatro métodos de previsão diferentes: Média Histórica, Modelo Regressivo, Redes Neurais Artificiais e Filtro de Kalman através de dois indicadores, Erro Relativo Médio e Erro Relativo Máximo e a técnica de Redes Neurais Artificiais se mostrou mais eficiente do que os métodos "lineares" (Erro Relativo Médio com RNA - 11,1\%).

Nesse caso, o autor até adotou métodos matemáticos mais robustos que a "lógica tradicional", mas foi necessário estimar um dado secundário, "tempo de embarque", que também influencia no fenômeno, mas torna a modelagem mais complexa. 0 método do autor considerou como dados de entrada, distâncias fixas entre os pontos de parada que também restringe ao problema do fretamento que tem rotas flexíveis, não precisam necessariamente parar em todos os pontos de parada previstos por exemplo.

Estudo de Seema et al. (2009), que desenvolveram um modelo para prever o tempo de chegada do veículo em um dado ponto de parada a partir dos dados de tempo de chegada aos pontos anteriores. Tal estudo considerou como entradas (inputs): a posição instantânea do veículo (latitude e longitude), à distância (m) percorrida do ponto anterior ao atual, à hora em que passou pela posição instantânea, sua velocidade e altitude, dados estes extraídos do sistema de rastreamento embarcado no veículo. Seema et al. (2009). 0 erro relativo médio entre os dados estimados e os dados apontados foi de $23 \%$.

Gurmu (2010) em sua modelagem descreve a arquitetura da RNA que utiliza como entradas para treinamento da rede: a) intervalo do dia em que o veículo está circulando (ex. pico da manhã, pico da tarde); b) ID do ponto de parada em que o veículo está passando no momento; c) tempo que o veículo levou do início da rota até chegar ao ponto atual e; d) 0 ID do ponto de parada que se deseja estimar o tempo de chegada. A saída da rede foi: o tempo que o veículo levou pra ir do ponto atual até o ponto de parada que se deseja estimar o horário da chegada. O valor encontrado para o Erro Relativo Médio foi $18,3 \%$. Segundo o mesmo estudo, os erros foram maiores que a média de 18,3\% quando se estimou tempos de viagens menores (<10 minutos) devido a vários fatores, a exemplo do mesmo autor, "um ônibus pode esperar por 1 minuto num semáforo, onde geralmente pode levar 2 minutos para atravessar" (Gurmu, 2010).

Se o objetivo é a previsão de algo que irá acontecer (no caso, hora: minuto em que o veículo chegará a um dado ponto) Seema (2009) adiciona a modelagem insumos desnecessários à modelagem e que podem, em um dado momento, influenciar negativamente na modelagem, é o que sugere quando se avalia o erro de previsão encontrado em tal estudo e o erro encontrado nos resultados do estudo de caso deste artigo. Outro ponto que pode limitar a modelagem foi o uso das coordenadas de pontos de parada pré-fixados.

Outro ponto observado nas experiências anteriores e que não se explorou a parametrização de variáveis que influenciam na forma de aprendizado da RNA como a Taxa de Aprendizado e o Momentum ou mesmo a construção de uma árvore de testes que explore opções diferentes de seleção de dados de entrada e saída. 0 uso da técnica da "validação cruzada" também não é mencionado nos experimentos anteriores. Tais fatores são contribuições do presente trabalho.

\section{Estudo de Caso}

\section{1. Área de estudo e rota escolhida}

Neste experimento, propõe-se estimar o instante em que um veículo (ônibus), que está executando uma determinada rota atingirá um ponto de controle pré-estabelecido. Para este estudo de caso, escolheu-se uma rota de ônibus que faz o transporte "indústria-residência" de funcionários de uma empresa instalada no município de Parauapebas, sudoeste do estado do Pará. Com aproximadamente $20 \mathrm{~km}$ de extensão, esta rota é realizada de segunda feira à sexta feira, no início da jornada de trabalho e "desfeita" ao final do expediente na saída. Usaram-se apenas as informações que estavam disponíveis em tempo real: a) localização do veículo (coordenadas planimétricas fornecidas por um receptor GPS) e b) hora em que o veículo passou pela referida localização (ponto de controle) através de equipamento embarcado - AVL (Automatic Vehicle Location).

Com o objetivo de estimar o instante de chegada do veículo até o ponto de controle, adotou-se este instante como saída da rede neural (variável dependente) e como entradas (variável independente), consideraram-se os dados disponíveis captados pelo sistema de rastreamento dos veículos ao longo do percurso (do ponto inicial da rota até o ponto de controle) que são: a) latitude de um dado ponto ao longo da rota; b) longitude do mesmo ponto e; c) Hora: Minuto em que o veículo passou por tal ponto.

A escolha dos dados de entrada para a etapa de treinamento da rede neural foi realizada obedecendo-se o seguinte critério: para um dado dia mediram-se várias posições (longitude, latitude) aleatórias ao longo da rota e o instante em que o veículo passou por tais pontos do percurso. Associou-se então este instante (hora: minuto) em que o veículo chegou ao ponto de controle pré-estabelecido nesse mesmo dia. Em um segundo dia, para a mesma rota, utilizou-se outra posição do mesmo percurso escolhida aleatoriamente e, fazendo a mesma associação para o instante (hora: minuto) que o veículo passou pelo ponto de controle no segundo dia, assim foi feito durante um período de 8 dias, como se encontra representado esquematicamente na Figura 01. As coordenadas do ponto de controle não entram no modelo, pois sua posição é a mesma em todos os 8 dias observados e o que varia de fato é a hora em que o veículo chegou este ponto. 


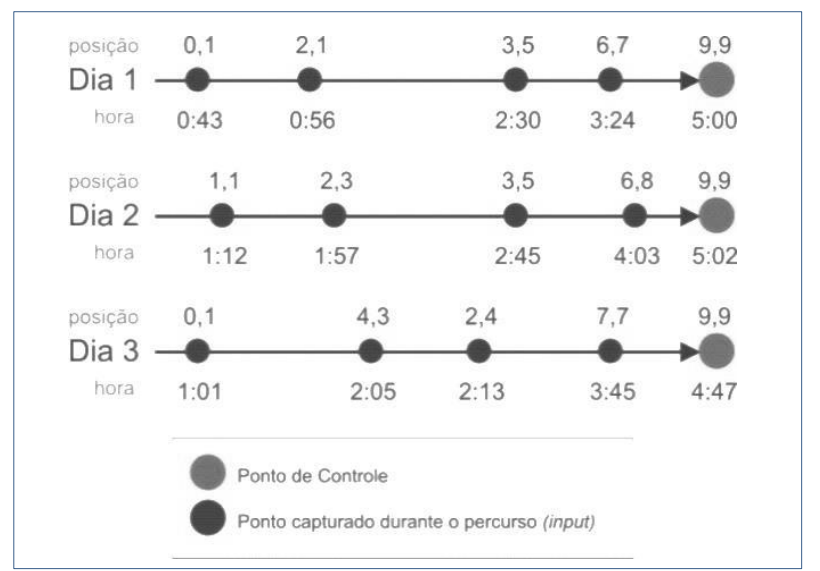

Figura 1 - Esquema parcial dos dados utilizados no treinamento da RNA

\subsubsection{O aplicativo computacional Easy-NN}

Neste trabalho usou-se o aplicativo EasyNN-Plus versão 9.0d, desenvolvido e comercializado por Neural Planner Software Ltda para a modelagem (treinamento/validação e teste) da rede neural. Esse aplicativo computacional permite o uso de redes de múltiplas camadas (Multilayer Perceptron - MLP), bem como possibilita a inclusão de até três camadas intermediárias. 0 algoritmo de aprendizado usado é do tipo backpropagation e, de acordo com informações do desenvolvedor, utiliza a função logística sigmoidal como função de ativação.

\subsubsection{Construindo uma árvore de testes}

Uma árvore de testes nada mais é do que um resumo que mostra que variações de treinamentos foram realizadas. 0 nome árvore se dá, pois o desenho se parece com uma estrutura de plantas com galhos derivando de um caule. Neste trabalho adotou-se a chamada "Validação "Cruzada" (Hayki 2005) onde se divide o conjunto total de dados disponíveis (no caso, um total de 1940 registros) em três subconjuntos para as etapas de treinamento (1397), validação (349) e teste (194), foram realizadas 3 seleções aleatórias diferentes caracterizando o primeiro nível da árvore de testes. A soma dos dois primeiros conjuntos de dados apresentados à rede neural garantem a proporção recomendada em HAYKIN (2005) que é de 80\% (treinamento+validação) e 20\% (teste).

Para definir o número de neurônios na camada intermediária, adotaram-se como ponto de partida, as sugestões de Nielsen (1989) apud Da Silva (2003) onde afirma que "a camada oculta deve ter por volta de (2i+1) neurônios, onde i é o número de variáveis de entrada" e Lippiman (1987) apud Da Silva (2003) afirma que uma camada oculta, "deverá ter s.(i+1) neurônios, onde s é o número de neurônios de saída e i o número de neurônios de entrada”. , a adoção das duas referências, resultou em duas MLP's com uma camada intermediária; a primeira com 7 (sete) neurônios e a segunda com 4 (quatro) neurônios.

Visando cobrir mais condições de testes que as sugeridas pela bibliografia, às três seleções foram treinadas com 4, 5, 6, 7 , $8,9,10,15,20,25,30,35,40,45,50,55,60,65,70,75,80,85,90,95,100,150$ e 200 neurônios na camada intermediária. Cada treinamento foi realizado inicialmente até 120 ciclos assumindo taxa de aprendizado de 0.60 e Momentum 0.80, opção padrão do aplicativo computacional usado. Em uma segunda etapa da árvore de testes, identificou-se qual topologia neural, dentre as usadas, possui a condição de treinamento mais adequada e foi refeito o treinamento variando-se os valores dos parâmetros Momentum e Taxa de Aprendizado em 0,10;0,20;0,30;0,40;0,50;0,60;0,70;0,80 e 0,90 para ambas os parâmetros.

\subsubsection{Indicador de qualidade do Modelo}

Para aferição da qualidade do modelo proposto, fez-se uso dos dados relativos ao subconjunto de teste, que não foram apresentados à rede durante as fases de treinamento e validação (calibração). Nesta etapa foram apresentadas à rede neural, com seus parâmetros (pesos) já calibrados, apenas as entradas deste subconjunto (teste), compararam-se então as saídas estimadas pela RNA aos dados reais disponíveis (horários de chegada dos veículos).

Diversas medidas de erro podem ser utilizadas para se identificar a topologia mais adequada e encontrar aquela que possui melhor desempenho na predição de dados (Bocanegra, 2002; Jales, 2009), contudo, neste estudo adotou-se o Erro Relativo Médio - ERM (Relative Mean Error - RME) que tem por objetivo calcular "a média das diferenças entre valores estimados pelas redes neurais e os valores observados" (Akamine 2005).

\subsection{Apresentação e análise de resultados}

A primeira seleção apresentou o menor ERM, a Figura 4 mostra que o aumento no número de neurônios na camada intermediária não melhoram os resultados de tal indicador. 0 ERM da seleção 1 chegou a 0,285\%, sendo o menor resultado quando se utilizou 9 neurônios na camada intermediária, as variações seguintes mantêm o mesmo resultado para seleção. (Figura 2) 


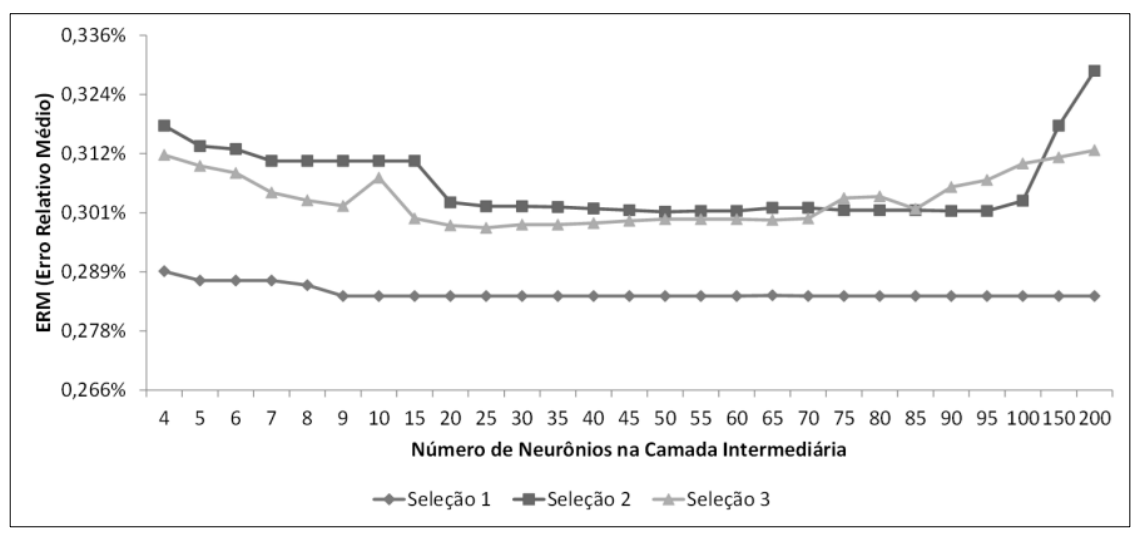

Figura 2 - Variação do ERM em função da variação do número de ciclos para as duas topologias testadas

Na segunda etapa, escolheu-se a topologia com 9 neurônios e refez-se uma bateria de treinamento até 120 ciclos variando os atributos de Momentum e Taxa de Aprendizado em num total de 81 RNA's. (Tabela 01). A variação que obteve o menor valor de ERM foi 0,205\% com 0,10 e 0,10 para Taxa de Aprendizagem e Momentum respectivamente.

Tabela 1 - Resultados dos ERM variando Momentum e Taxa de Aprendizagem)

\begin{tabular}{|c|c|c|c|c|c|c|c|c|c|c|}
\hline & & \multicolumn{9}{|c|}{ Momentum } \\
\hline & & 0,10 & 0,20 & 0,30 & 0,40 & 0,50 & 0,60 & 0,70 & 0,80 & 0,90 \\
\hline \multirow{9}{*}{ 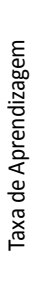 } & 0,10 & $0,20 \%$ & $0,21 \%$ & $0,21 \%$ & $0,22 \%$ & $0,22 \%$ & $0,34 \%$ & $0,22 \%$ & $0,23 \%$ & $0,27 \%$ \\
\hline & 0,20 & $0,23 \%$ & $0,23 \%$ & $0,23 \%$ & $0,23 \%$ & $0,23 \%$ & $0,23 \%$ & $0,30 \%$ & $0,26 \%$ & $0,30 \%$ \\
\hline & 0,30 & $0,24 \%$ & $0,24 \%$ & $0,23 \%$ & $0,23 \%$ & $0,24 \%$ & $0,24 \%$ & $0,24 \%$ & $0,27 \%$ & $0,33 \%$ \\
\hline & 0,40 & $0,24 \%$ & $0,24 \%$ & $0,24 \%$ & $0,24 \%$ & $0,24 \%$ & $0,25 \%$ & $0,26 \%$ & $0,27 \%$ & $0,34 \%$ \\
\hline & 0,50 & $0,34 \%$ & $0,24 \%$ & $0,24 \%$ & $0,25 \%$ & $0,25 \%$ & $0,25 \%$ & $0,27 \%$ & $0,28 \%$ & $0,36 \%$ \\
\hline & 0,60 & $0,24 \%$ & $0,24 \%$ & $0,24 \%$ & $0,25 \%$ & $0,26 \%$ & $0,26 \%$ & $0,27 \%$ & $0,28 \%$ & $0,36 \%$ \\
\hline & 0,70 & $0,36 \%$ & $0,25 \%$ & $0,25 \%$ & $0,25 \%$ & $0,26 \%$ & $0,26 \%$ & $0,27 \%$ & $0,29 \%$ & $0,29 \%$ \\
\hline & 0,80 & $0,25 \%$ & $0,25 \%$ & $0,25 \%$ & $0,26 \%$ & $0,26 \%$ & $0,27 \%$ & $0,28 \%$ & $0,28 \%$ & $0,36 \%$ \\
\hline & 0,90 & $0,36 \%$ & $0,25 \%$ & $0,26 \%$ & $0,26 \%$ & $0,27 \%$ & $0,27 \%$ & $0,28 \%$ & $0,28 \%$ & $0,30 \%$ \\
\hline
\end{tabular}

Buscando-se identificar como a distância, em que o veículo está do ponto de controle, influencia na qualidade do modelo, calculou-se o ERM para intervalos de tempo de 15 minutos conforme Figura 05. No caso das classes com 1h30 e 1h45, não houve entradas no conjunto de dados de validação que estivessem nessas classes (Figura 3).

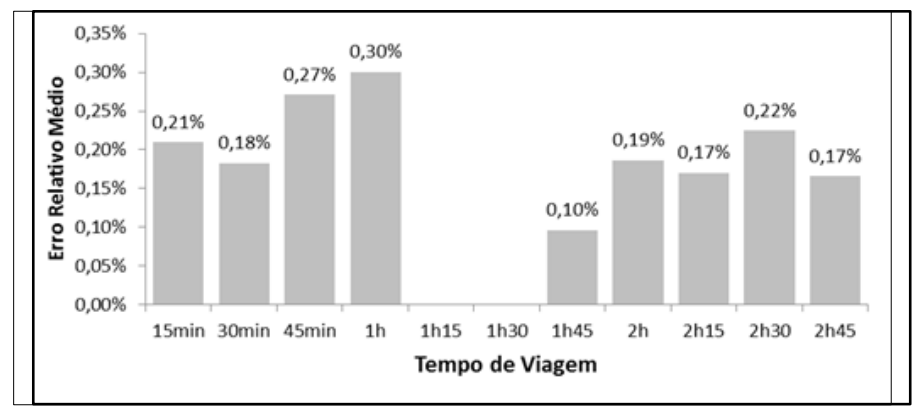

Figura 3 - Variação do ERM em relação ao tempo de viagem. A esquerda o ínicio do percurso e a direita, próximo ao ponto de controle

Na estratificação do ERM em intervalos de tempo de 15 minutos, observa-se que o modelo aumenta o erro à medida que se aproxima do ponto de controle (final da rota) isso ocorre provavelmente porque a rota em questão vem de uma região menos adensada para uma região mais adensada da cidade. 0 ponto de controle está situado numa região com maior volume de veículos e maiores conflitos de tráfego potencializando os fatores externos que influenciam na execução da rota.

\section{Conclusões e Recomendações}

O modelo foi bem-sucedido, o ERM de 0,2\% encontrado no presente trabalho é inferior ao encontrado na bibliografia pesquisada para estudos similares e também se for comparado com outras técnicas. Na prática significa que modelo gera estimativas com erros médios que não superam 1 minuto. 0 erro é significativamente inferior ao encontrado na bibliografia e nas experiências anteriores e há duas possibilidades;

a) A captação aleatória do posicionamento do veículo ao longo do percurso foi positiva à modelagem do fenômeno, pois permitiu que a rede "generalizasse" o seu conhecimento do trajeto, ou seja, ela aprendeu a hora de chegada ao ponto de controle considerando a hora em que o veículo passou em diferentes pontos do percurso, em diferentes horários. Dessa forma, a RNA "absorveu" os fatores que influenciam na execução do trajeto durante o aprendizado. Esse aprendizado é mais limitado se fosse apresentada à rede, informações dos mesmos pontos de parada em diferentes dias ou; b) Pela limitação na 
quantidade de dias considerados na modelagem e sendo dias próximos, a RNA não "aprendeu" as flutuações do tráfego ao longo do ano ou as características de diferentes motoristas/veículos que executam a mesma rota. A modelagem ficou "especialista" ocorrendo um fenômeno parecido com "overfitting".

O conjunto de dados usado está limitado a apenas um trajeto, sugere-se que se amplie o experimento, incluindo-se dados dos outros 24 trajetos possíveis e em períodos de tempo mais abrangentes (semanas, meses, anos) conforme estudos de YU et al (2011), essa sugestão também permite excluir ou validar a hipótese do "overfitting". Do ponto de vista prático, fazer com que a RNA aprenda a influência de tais fatores indiretamente, é necessário, tendo em vista que adquirir dados em tempo real sob as condições do trânsito e incorporá-los ao modelo é praticamente inviável para grande maioria das cidades brasileiras.

\section{Referências}

Akamine, A. (2005) Explorando alternativas para construção de modelos neurais de interação espacial. Dissertação de Mestrado, EESC-USP, São Carlos, 2005.

Bocanegra, C. W. R. (2002) Procedimentos para tornar mais efetivo o uso de Redes Neurais Artificiais em planejamento de trans portes. Dissertação de Mestrado. USP-São Carlos, Departamento de Engenharia de Transportes. São Carlos-SP, Brazil.

Da Silva, C. A. U. (2003) Um método para estimar observáveis GPS usando Redes Neurais Artificiais. Tese de doutorado. USP-São Carlos, Departamento de Engenharia de Transportes. São Carlos-SP, Brazil.

Haykin (2001) Neural Networks, A Comprehensive Foundation. Second Edition, Pearson Education, McMaster University, Hamilton, Ontario, Canada.

Jales, A. W. L. (2009), Estimação de Volumes de Tráfego com base na Morfologia Urbana. Estudo de caso: Cidade de Fortaleza-CE. Fortaleza, 2009. Dissertação de Mestrado, Programa de Mestrado em Engenharia de Transportes, Universidade Federal do Ceará, FortalezaCE, Brazil.

Motinho, S. J., Silva, H. B.,(2011) Mineração de dados e Inteligência Artifical para previsão do tempo de chegada do Ônibus Urbano entre Paradas Consecutivas. E-xacta, Editora UniBH, Belo Horizonte-MG, Brazil.

Weingang, L. Yamashita, Y. Silva, O. Q.,Prazeres, M. A., Oliveira, D. C. S. (2004). Implementação do Sistema de Mapeamento de uma Linha de Ônibus para um Sistema de Transporte inteligente. XXVIII Seminário Integrado de Software e Hardware, 2004, vol.38, n.2, Fortaleza, pp. 163 186, Brazil.

Yu, B., Lam, W. H. K., Tam,, M. L., (2011) "Bus arrival time prediction at bus stop with multiple routes" Transportation Research Part C, ELSEVIER,

Seema S. R. and Sheela A., (2009) “Dynamic Bus Arrival Time Prediction Using GPS Data”, College of Engineering Trivandrum, 10th National Conference on Technological Trends, Kerala, India.

Gurmo, Z., K., (2010) “Dynamic Prediction of Travel Time for Transit Vehicles in Brazil Using GPS Data”, Department of Civil Engineering \& Management, University of Twente, Thesis.

Shalaby, A.,(2004) "Prediction Model of Bus Arrival and Departure Times Using AVL and APC Data”, Journal of Public Transportation, Vol. 7, No. 1. University of South Florida, United States.

\section{Abstract}

The research's objective was to develop a model of bus arrival prediction to employees' transportation with charter regime. For this, was used a mathematical model based on Artificial Neural Networks. Previous experiments using RNA application to modeling this kind of problem considered as data's input "static" information of the route, such as the position of points of predetermined stops, the distance between them and the average speed route previously analyzed. The research's contribution was to develop a learning model considering as input data, any vehicle location (longitude and latitude) along the route and the time in which it went through the same coordinated, becoming the most dynamic and simplified model to be reproduced and incorporated into vehicle tracking tools that use global positioning (GPS). Another methodological contribution was structuring a "test tree", this test considered variations in the typology, in the values for Learning Rate and "Momentum". The result achieved reached a predictive model with mean relative error of less than 1\%.

Key words: artificial neural networks; bus arrival; time prediction. 